\title{
Yerberito: audiovisual transmedia para difundir el uso sostenible de plantas medicinales
}

\section{Yerberito: audiovisual transmedia to spread the sustainable use of medicinal plants}

\author{
TIPO DE TRABAJO: Comunicación. \\ PALABRAS CLAVE \\ Transmedia, arte, audiovisual, ciencia, tecnología, plantas medicinales.
}

KEY WORDS

Transmedia, audiovisual, art, science, technology, medicinal plants.

RESUMEN

Yerberito es un proyecto transmedia que vincula arte, ciencia y tecnología, es el resultado de una investigación en la Universidad Autónoma de Bucaramanga. El proyecto pretende promover el uso sostenible de las plantas medicinales nativas colombianas en pro de su conservación y de la biodiversidad. La investigación interdisciplinar se divide en dos partes que se relacionan con las fases metodológicas y de diseño del proyecto: los estudios ambientales y botánicos en los que se clasificaron las plantas y como proyecto aplicado la creación de una obra audiovisual. Yerberito se propone como una vía en el proceso de divulgación de resultados de las ciencias naturales al unir sinergias con la investigación creación propia de las artes audiovisuales.

\begin{abstract}
La plataforma tiene tres nodos principales: el primero un documental interactivo (no lineal) en el que, a través de una polifonía de voces de adultos mayores, comercializadores de hierbas y habitantes rurales, cuentan los diferentes usos de las plantas medicinales, conocimiento que les ha sido transmitido a través de la tradición oral por generaciones. Mostrando los usos que la comunidad les da a las plantas medicinales en su cotidianidad y la relación que ellos establecen con la naturaleza. En el segundo nodo; el usuario entra en un museo virtual o herbario ilustrado que contiene información biológica de 13 plantas medicinales nativas. Finalmente, en el tercer nodo se puede descargar y ampliar la experiencia de manera inmersiva con una aplicación móvil de realidad virtual que complementa el documental interactivo con ambientes naturales en los cuales se encuentran las plantas, sonidos y fotografías $360^{\circ}$, teniendo la posibilidad de reconocer el ecosistema, los espacios y los sonidos naturales. El proyecto emplea videos, ilustraciones, fotografías y relatos dispuestos en un sitio web y en una aplicación móvil de realidad virtual.
\end{abstract}

\section{ABSTRACT}

Yerberito is a transmedia project that links art, science and technology, and is the result of research at the Universidad Autónoma de Bucaramanga. The project aims to promote the sustainable use of Colombian native medicinal plants for their conservation and biodiversity. The interdisciplinary research is divided into two parts that are related to the methodological phases and the project design: the environmental and botanical studies in which the plants were classified, as an applied project the creation an audiovisual. Yerberito is proposed as a way in the process of dissemination of results of the natural sciences by joining synergies with research own creation of the audiovisual arts.

The platform has three main nodes: the first an interactive documentary (non-linear) in which, through a polyphony of voices of older adults, marketers of herbs and rural inhabitants. They tell about the different uses of medicinal plants, to knowledge that It has been transmitted through oral tradition for generations. Showing the uses that the community gives to medicinal plants in their daily lives and the relationship they establish with nature. In the second node; the user enters a virtual museum or illustrated herbarium that 
contains biological information of 13 native medicinal plants. Finally, in the third node you can download and expand the experience in an immersive way with a mobile virtual reality application that complements the interactive documentary with natural environments in which the plants, sounds and photographs are $360^{\circ}$, to having the possibility of recognizing the ecosystem, the spaces and the natural sounds. The project uses videos, illustrations, photographs and stories arranged on a website and a virtual reality mobile application.

\section{INTRODUCCIÓN}

En Colombia se han identificado alrededor de 6.000 plantas con propiedades medicinales de uso popular. Sin embargo, sólo un pequeño porcentaje de estas y sus derivados son conocidas entre la población. Resultan escasos los estudios etnobotánicos de especies vegetales utilizadas con fines medicinales y la aproximación al conocimiento en torno al uso medicinal de las plantas se ha dado por la transmisión oral de saberes entre los individuos de diferentes generaciones. Hasta el momento en el oriente colombiano se han registrado 118 especies repartidas en 47 familias botánicas. Las plantas tienen 133 nombres locales y 164 usos diferentes. Las diez categorías de uso que agrupan mayor número de especies fueron problemas digestivos, respiratorios, traumas, problemas cardiovasculares, cutáneos, hepáticos, renales, dolor y ansiedad. Las personas reconocidas por la comunidad para tratar las dolencias suelen ser las mujeres madres de familia, los hierbateros, las parteras, los sobanderos, los rezanderos y los secreteros. El mercado de plantas medicinales por tradición funciona en las plazas de mercado y se ha desarrollado otro mercado paralelo de fitoterapéuticos en tiendas naturistas y laboratorios.

Ante este panorama y con el fin que las plantas y sus propiedades no sean solo conocidas entre los ancianos, si no que los jóvenes conozcan y usen las plantas medicinales. Surgió la idea de realizar un audiovisual transmedia que difundiera y promoviera la conservación y el uso sostenible de plantas medicinales nativas. El proyecto pretendió acercar a nuevas generaciones al patrimonio natural a través de dispositivos audiovisuales que les permitieran realizar tareas de multiplicidad, simultaneidad y fragmentación de relatos, porque las narraciones no lineales suelen ser una opción narrativa atractiva para las nuevas generaciones.

Desde el año 2012, ha sido creciente y hay un incipiente pero prolífico desarrollo tanto en las iniciativas de producción, como de exhibición y de formación de audiovisuales transmedia en Colombia. La mayoría de las obras no lineales tiene como característica común la intención por preservar la memoria y salvaguardar el patrimonio del país, son pocos los audiovisuales transmedia que han abordado temas ambientales. La mayoría de los esfuerzos se concentran en el documental de denuncia y son de modalidad expositiva. Teniendo en cuenta esta serie de coincidencias y necesidades se realizó un audiovisual que ampliara la experiencia inmersiva en el ecosistema de las plantas medicinales.

\section{METOdologíA}

El proyecto se abordó de manera secuencial en dos etapas: la primera relacionada con la investigación biológica; y la segunda parte relacionada con la investigación creación de la obra audiovisual transmedia. En la etapa biológica primero se eligieron los municipios objeto de la investigación teniendo en cuenta dos pisos térmicos diferentes. Posteriormente se determinaron cuáles eran las plantas nativas más representativas, que fueran aptas para adaptarse progresivamente al ecosistema del Cañón del Chicamocha, en el oriente de Colombia.

En la segunda etapa de la investigación se realizó un proyecto transmedia en tres sub-etapas acordes a la metodología de la creación de una obra audiovisual: preproducción, diseño de interfaz, escritura del guion transmedia, plan de producción y plan de grabación. Luego en la producción se grabó en los ecosistemas de las plantas, se realizaron time lapse e ilustraciones de las hierbas. Finalmente, en la postproducción se realizó la edición no lineal, se ensamblarán las piezas en la interfaz, se hizo la programación, la sonorización, la corrección de color de video, el diseño gráfico y se subió al servidor web.

\section{DESARROLLO}

De acuerdo a la naturaleza del proyecto de investigación interdisciplinar, se abordará desde dos perspectivas: por un lado, desde los estudios ambientales y botánicos. Por otro lado, desde la creación audiovisual y particularmente desde la narración de documental no lineal. Desde la perspectiva biológica, se contó con la asesoría e investigación de una Doctora en Biología, quien respaldó teóricamente el proyecto audiovisual. En ese sentido, la investigadora estableció la taxonomía de 13 plantas medicinales que posteriormente fueron las plantas seleccionadas para el museo virtual. Las plantas fueron clasificadas de acuerdo a seis de sus efectos: 
astringentes, alcalinizadoras, tónicas, diuréticas, diaforéticas y nerviosas. En consecuencia, las especies seleccionadas fueron: eneldo, poleo, jengibre, ruda, boldo, tilo, diente de león, nopal, orégano, pronto alivio, paico, ortiga y ruda. Con base en la investigación se determinó que una planta medicinal puede tener más de uno de estos efectos y su estudio ayuda a distinguir sus propiedades y se pueden utilizar en una gran variedad de formas (Chalela, 2010). Algunas plantas se usan frescas, mientras que otras se secan o se preparan para su conservación.

Por otro lado, teniendo en cuenta que la otra perspectiva teórica sobre la que se fundamenta el proyecto de investigación es desde las artes audiovisuales, es preciso enfatizar que las nuevas formas de comunicación digital han hecho que las narraciones audiovisuales evolucionen hasta relatos de base intertextual, red de textos, videos, audios, etc. (Scolari, 2013). Por lo tanto, en el audiovisual contemporáneo el rol que adquiere el espectador- usuario se modifica, porque pasa de tener un rol pasivo a uno activo del cual se requiere una participación constante en las propuestas narrativas. En ese sentido, (Giannetti, 2002) plantea que la conectividad, la hipertextualidad y la interactividad son modos que están vinculados a la autoría descentralizada y a la participación colectiva.

En consecuencia, los proyectos expandidos se convierten en una herramienta eficaz en los procesos educativos, porque además de ser una experiencia lúdica y entretenida, tiene una intención marcadamente pedagógica y ante todo una experiencia didáctica. En ese sentido, el proyecto expandido Yerberito cuenta ya con equipo interdisciplinar conformado, que ha desarrollado previamente trabajos similares de narración no lineal y realidad virtual.

\section{TRANSMEDIA PROPUESTA PRÁCTICA}

En el género documental difícilmente aplica el término guion, en cambio suele utilizarse un esbozo de estructura documental que sirve como ruta o mapa sobre la interpretación de la realidad que se intenta mostrar con la obra audiovisual. En consecuencia, se planteó la estructura narrativa del proyecto documental Yerberito, un mapa de contenidos y navegación estructuras acordes a la naturaleza de un documental expandido.

La estructura de Yerberito es no lineal y se asemeja en una especie de cartografía creativa. Para el diseño de la interfaz se hizo una ilustración del subsuelo con las raíces de las plantas, que sirvió a su vez como metáfora visual. El proyecto transmedia contó con diversos recursos audiovisuales dispuestos en un sitio web interactivo en internet y en una aplicación móvil de realidad virtual inmersiva para brindar una experiencia integral al usuario. Al ser un proyecto expandido, está concebido para privilegiar la experiencia del usuario, quien tiene la opción de navegar entre los diferentes contenidos de acuerdo a su preferencia. El proyecto en la web es rizomático y los contenidos tienen una navegación reticular (Orihuela y Santos, 2000), que permite que los usuarios puedan navegar entre videos, ilustraciones, paisajes sonoros de los ecosistemas, fotografías, etc. Además, la experiencia del usuario se amplía por medio de una App de realidad virtual.

La plataforma contiene un documental interactivo (no lineal) en un entorno $360^{\circ}$ en el que, a través de una polifonía de voces de adultos mayores, comercializadores de hierbas, habitantes rurales y científicos, cuentan los diferentes usos de las plantas medicinales, conocimiento que les ha sido transmitido a través de la tradición oral. Asimismo, se diseñó un museo virtual o herbario ilustrado con información botánica general de 13 plantas medicinales. El proyecto busco ampliar la experiencia inmersiva con una App en realidad virtual que complementa el documental interactivo, en la aplicación móvil el usuario entra en los ecosistemas de las plantas, teniendo una espacialización sonora y visual del hábitat. Al abrir la aplicación los usuarios inician en un escenario de 360 grados, donde se encuentran un ambiente ilustrado que representa el ambiente natural.

\section{MAPA DE CONTENIDOS Y NAVEGACIÓN}

Por el volumen de datos de la interfaz, fue preciso establecer el diseño de la información y el diseño de la interacción recurriendo a una metáfora de navegación estimulante para el usuario, en este caso las raíces de las plantas y el subsuelo. Para el diseño de interfaz gráfica se optó por utilizar un conjunto de imágenes y objetos gráficos ilustrados para representar la información general de las plantas y las opciones disponibles, con el objetivo de proporcionar un entorno visual sencillo que permitirá la comunicación con el sistema operativo de cualquier computador. La sencillez y la claridad en la interfaz del documental expandido fueron imprescindibles para el acceso fácil de los usuarios a los contenidos. Para la experiencia interactiva se diseñaron los mapas de navegación por un lado del documental interactivo que está en la web y, por otro lado, de la aplicación con realidad virtual.

En la experiencia web el usuario puede avanzar fácilmente en las rutas posibles, es él quien elige el camino que quiere seguir. En el diseño esquemático del contenido interactivo, se dispusieron elementos gráficos en la interfaz tipo íconos y cada uno fue rotulado en función de la sencillez, de la usabilidad y de la facilidad de navegación. Asimismo, el estándar de HTML5 permitió el uso en diferentes 
dispositivos digitales: computadores, tabletas y teléfonos móviles. Los modelos de interacción variaron según las posibilidades que tenía el espectador-usuario de modificar o transformar a partir de su intervención o con un simple tránsito entre las rutas dispuestas sobre los contenidos, que no permiten alteraciones al proyecto. Es decir, la modalidad de interacción depende de las herramientas con las que cuente el usuario para crear un efecto perdurable en el espacio y el tiempo de la obra audiovisual. De acuerdo a las 3 modalidades de interacción (Gifreu, 2013) el proyecto Yerberito tiene un tipo de interacción generativa contributiva y un modo de interacción alto.

La realidad virtual inmersiva, que puede ser descargada gratuitamente desde el entorno web a través de una aplicación móvil APK y a través de Google Play. Al instalar la aplicación se abre la experiencia en realidad virtual en el teléfono móvil, el cual se combina con las Gafas VR que funcionan como cascos de realidad virtual. El dispositivo celular se convierte en el sistema que procesa y genera la Realidad virtual (VR), donde los usuarios tienen la sensación de estar inmersos en cada escena, interactuando con los contenidos del documental y con los objetos que contiene. El software para la realización de la Aplicación será UNITY, el cual como un motor de videojuego multiplataforma se constituye en el desarrollo de VR más utilizado en el mercado debido a las herramientas de desarrollo y al pipeline de renderizado altamente optimizado de UNITY y las capacidades de interacción rápida con objetos multimedia.

Se pensó en una aplicación para dispositivos móviles gracias a los sensores que poseen los celulares, como el caso del giroscopio o acelerómetro, que son capaces de detectar los movimientos de la cabeza del usuario generando así la sensación de estar en otro ambiente y de poder seleccionar la ruta que elija. En consecuencia, este tipo de experiencia crea una visión 3D estereoscópica con profundidad, escala y paralaje. A diferencia de los televisores 3D o de una película, la visión se consigue mediante la presentación de imágenes únicas y paralelas para cada ojo, igual a la forma en que nuestros ojos perciben las imágenes en el mundo real, creando así una experiencia única y más natural.

La programación de Yerberito se realizó con el software francés Klynt, que funciona como un mapa interactivo para disponer las secuencias como un mapa mental, propendiendo así por una experiencia de usabilidad alta. Klynt funciona a través de una cuadrícula para un nivel de interacción en el que se pueden conectar varios contenidos multimedia en una misma interfaz. Klynt están basado en HTML5 que ha facilitado la rapidez en la carga de contenidos, y la integración multiformato e interacción audiovisual.

\section{PROPUESTA TÉCNICA DEL AUDIOVISUAL}

Teniendo en cuenta que las protagonistas de la historia son las plantas, el documental expandido se planteó desde la observación y la contemplación. En ese sentido, para la propuesta fotográfica la cámara privilegió el hábitat y a través de time lapse de las 13 plantas seleccionadas se mostró su crecimiento usando un lente macro. La presentación de los ecosistemas se hizo con cámara en movimiento con el fin de dar dinamismos a las imágenes de la naturaleza. El uso de primeros planos fue usual para mostrar las hierbas. Mientras que a los personajes que se relacionan con las plantas: los cultivadores, los consumidores, los comercializadores se realizó con planos medios y generales con el fin de mostrar la atmosfera, las dinámicas del lugar y la relación que cada uno de los personajes establece con las plantas. La propuesta general de iluminación recayó en el uso de luz natural para preservar la conservación de las plantas.

Para la propuesta de sonido se contemplaron 4 factores: la captura de sonido directo, la postproducción de sonido, la musicalización y el entorno sonoro de la interfaz en la web. Con el fin de recrear el paisaje sonoro natural y el ecosistema de las plantas se dio prelación a la captura de sonido ambiente, a la brisa, el agua, entre otros elementos. Por medio del sonido se construyó un ambiente que permitiera al usuario- espectador estar inmerso en el contexto de los ecosistemas de las plantas y en el contexto de los personajes. El uso de entrevistas y sonidos ambientes son los elementos sonoros más representativos. Para el diseño sonoro de la interfaz digital, se enfatizó en sonidos naturales para cada uno de los entornos. Para los enlaces o hipervínculos se emplearon en ambientes propios de la naturaleza, en la propuesta de musicalización se utilizaron otros elementos digitales.

Por último, de acuerdo a la estructura que se planteó tanto de navegación, como de interacción de contenidos, se realizó el montaje buscando dar coherencia a cada una de las líneas narrativas. Las imágenes fueron editaras con un ritmo contemplativo para las plantas y más acelerado con los personajes humanos. Sin embargo, no se mantuvo una estructura rígida, se desarrolló cada personaje y planta según lo requería el discurso narrativo, las imágenes seleccionadas no sólo sirven de apoyo a la voz off de cada personaje, sino que además soportan el discurso oral. 


\section{CONCLUSIONES}

Yerberito es un estudio que cohesiona el arte, la ciencia y la tecnología para promover la conservación de la biodiversidad. El transmedia se constituye en una figura que sirve de enlace entre las posibilidades que ofrece la narración no lineal, el empleo de recursos tecnológicos y la necesidad de promover el uso sostenible del patrimonio natural de una forma educativa.

El proyecto ayuda a fomentar y proteger el ecosistema, la biodiversidad y el patrimonio natural; el audiovisual tiene un impacto ambiental y promueve el uso de los recursos naturales para la salud. Temáticamente en Colombia son pocos los proyectos audiovisuales que abordan como protagonistas las plantas nativas nacionales y menos aún las plantas medicinales, Yerberito es el primer museo virtual dedicado a especies botánicas nativas y no hay precedentes en un proyecto similar en el país. En ese sentido, la plataforma audiovisual expandida se planteó como un proyecto de creación artística y además en una plataforma de divulgación científica. Yerberito es un espacio que promueve el estudio y análisis de las imágenes de las ciencias naturales a través de la fotografía, la ilustración y la imagen en movimiento.

El diseño de la App de realidad virtual, incluida dentro del proyecto, también implica un factor diferenciador de la propuesta por la apropiación social del conocimiento que genera. Asimismo, los espacios inmersivos en $360^{\circ}$ con sonido son escasos y más aún en el área de documental, estás técnicas de espacialización suelen ser más utilizadas para el desarrollo de videojuegos. Es preciso señalar, que el término interacción no significa de acuerdo a los alcances de este proyecto expandido, lo mismo que participación. La interacción está más cercana al término colaboración porque modifica aquello que interviene y es un proceso en el que necesariamente existe implicación, una interactividad reactiva más cercana al hipermedia, a la hipernavegación y a la simulación.

La fragmentación, la simultaneidad y la multiplicidad fueron tres características, y casi condiciones, para realizar este proyecto interactivo. El diseño de la interfaz juega un papel relevante para la interacción porque del diseño y de la metáfora visual depende que la propuesta de interactividad resulte comprensible. La importancia de la interfaz radica sobre todo en que articula todos los contenidos; de su usabilidad y sencillez depende que el usuario comprenda cómo puede interactuar y acceder al material disponible.

Finalmente, el transmedia es una herramienta eficaz en los procesos educativos porque además de ser una experiencia lúdica y entretenida, tiene una intención marcadamente pedagógica y es ante todo una experiencia didáctica. Este tipo de formatos tienen la posibilidad de ser más llamativos para las nuevas generaciones que precisan interactuar de manera constante con contenidos en diferentes formatos.

\section{FUENTES REFERENCIALES}

Chalela, G. (2010). Uso y aprovechamiento de plantas medicinales promisorias como apoyo a la cadena de valor de los ingredientes naturales. Bucaramanga: Gobernación de Santander Neomundo.

Choi, I. (2009). Interactive documentary: a production model for nonfiction multimedia narratives. Intelligent technologies for interactive entertainment. Berlin: Springer Verlag.

Gaudenzi, S. (2009). Digital Interactive documentary: from representing reality to co-creating reality. Londres: University of Goldsmiths Centre for Cultural Studies.

Giannetti, C. (2002). Estética Digital, sintopía del arte, la ciencia y la tecnología. Barcelona: Associació de Cultura Conteporánia L'Agelot.

Gifreu, A. (2013). El documental interactivo. Barcelona: Editorial UOC.

Moreno, I., Andrade, V., Colorado, A. (2014). ArTecnología, conocimiento aumentado y accesibilidad. Madrid: Universidad Complutense de Madrid.

Muñoz, F. (2002). Plantas medicinales y aromáticas: estudio, cultivo y procesado. Madrid: Ediciones Mundi-Prensa.

Orihuela, J. y Santos, M. (2000). Introducción al Diseño Digital. Concepción y Desarrollo de Proyectos de Comunicación Interactiva. Madrid: Ed. Anaya Multimedia.

Scolari, C. (2013). Narrativas Transmedia. Barcelona: Deusto. 